\title{
Athletes' pride bridge: Network centrality analysis to clarify the societal values of sports after the 2011 disaster in Japan.
}

\author{
Koh Sasaki \\ Professor, Research Center for Health, \\ Physical Education and Sports, Nagoya University \\ Furo, Chikusa, Nagoya, Aichi, 4648601, Japan \\ Takumi Yamamoto \\ National Defense Academy, Yokosuka, Japan \\ Ichiro Watanabe \\ Tokyo City University, Tokyo, Japan \\ Takashi Katsuta \\ Japan Sport Council, Tokyo, Japan \\ Ichiro Kono \\ 2019 Rugby World Cup Organizing Committee
}

\begin{abstract}
This research builds on our previous study, examining recognition of social management and observes the interpretation of benevolent sports activities following Japan's 2011 earthquake and tsunami. After the incident, most sports and recreational activities were suspended; however, various benevolent sports activities were arranged to benefit the damaged areas. This study investigates the recognised human value structure of sports in situation of great public anxiety by applying the life management concepts of time perspective and hope. The results regarding the terminal values study suggest the greatest recognition of 'hope for the future', 'family bonds', 'excellence', 'global concern' and 'life force'. Furthermore, the instrumental values study suggest greatest recognition of the 'ambitious', 'courageous', 'self-reliant', 'competent' and 'respectful' that indicate concern for inner motivation and survival capability. Network analysis (graph theory and centering resonance analysis) presents a holistic evaluation method for the positional functions of societal values and organization. Lonely coaches and athletes could be supported by some social pride for their long term struggle for training under the pressure. Purely following the goal is a kind of heterogeneous and unique in a good sense. However, its mind is to co-evolve community and social philosophy. The originality may exert the power to connect society with intense change, high uncertainty, complex era. The value of sport life force means an extremely tactile information and create a direct communication community in the so-called information society.
\end{abstract}

Keywords: human values, sports, network centrality, correspondence analysis

\section{INTRODUCTION}

In recent years, several natural disasters have occurred frequently in Japan and the other countries. It might be the historical fate of the country located in the volcanic belt. Since the East Japan disaster on 11 March 2011, Japanese society has been at risk of losing collective hope for the future. This catastrophe caused much of the general public to refrain from all sports activities, even as various benevolent sports activities were immediately arranged to benefit the afflicted areas. Many national federations of sport, national teams and professional 
leagues held charity matches, along with providing local support and relief goods and serving affected residents through personal networking and various other donation activities. The present study builds on our previous works [1, 2], which examined the recognised human value structure provided by sports in this crisis situation by referring to the social management concepts of time perspective and values.

The study of hope and management of human values, as a social management tool, began in $2000[3,4]$. The purpose of this field of study is not to explore facile optimism but to consider the structure of positive and future-oriented thinking and its role in contributing to community rebuilding. The study of human values is an approach designed to clarify the cognitive beliefs that operate in decision making and dealing with conflicts [5]. Hope, a crucial human value, is recognised as a valuable motivator of life management activities in a crisis situation. The academic purpose of the present study is to identify the hope and human value structure in sports and its social impact.

As people live in a society impacted by various complex values, they must recognise and prioritise these values within their own social value system. This system has two dimensions: terminal values (end states of existence) and instrumental values (modes of conduct). This study adopted Rokeach's model [5] to operationalise these two dimensions. Rokeach's model includes terminal values such as 'hope for future', 'pride in country', 'true friendship', 'inner harmony', 'family bond', 'global concern' and 'accomplishment; lasting contribution' as attributed values as well as instrumental values such as 'broadminded' and 'forgiving' as concrete mentality and 'ambitious', 'courageous' and 'honest' as life skills. Individuals' holistic cognitive value chain structures for sports activities, including benevolence, would be expected to describe the relationship between success in sports and survival in society. For a discussion on human values, the study of hope or time perspective as a life management approach and the study of terror management [6] as biological ontology could be effective. Drawing on these viewpoints, this study discusses the value chain of ontological commitment to society's realistic survival.

\section{METHODS}

Rokeach's model contains 18 terminal and 18 instrumental values and suggests that their prioritization will be affected by the particular context. For example, 'pride in country' and 'global concern' would tend to assume higher priority in a situation of international conflict. Thus, to adapt Rokeach's model to Japan's current social conditions, the authors made various alterations to Rokeach's set of items. In the category of terminal values, the authors changed 'national security' (protection from attack) to 'pride in country' (to represent citizens' willingness to work together for their country's good). 'Happiness' was changed to 'hope for the future' so as to represent an ontological commitment to improving people's existence rather than an absolute state. 'World beauty' (beauty of nature and arts) was changed to 'world beauty' (beauty of human beings and nature). 'An exciting life' was changed to 'life force', 'a comfortable life' to 'prosperity', 'a world at peace' to 'global concern', 'salvation' to 'benevolence', 'mature love' to 'ideology/culture' and 'pleasure' to 'light-hearted'. Among the instrumental values, 'obedient' (dutiful, respectful) was changed to 'respectful' (dutiful) to mean proactive rather than passive willingness.

The subjects included three groups of people: national certified sports coaches $(\mathrm{N}=78$ : male = 43 , female $=35$, age $=2658$ years, average age $=41$ years $)$, university students in sport science $(\mathrm{N}=178$ : male $=105$, female $=73$, age $=18-21$ years, average age $=20$ years $)$ and university students in engineering $(\mathrm{N}=183$ : male $=93$, female $=90$, age $=1921$ years, average age $=20$ years). The research was conducted in October and November 2018. Subjects received an 
explanation of the study's structure and of various sports-related benevolent activities such as donations, charity matches and voluntary disaster relief activities. Next, they were asked, 'What types of values do you recognise in Japanese benevolent sports activities that intended to help affected members of society after the 2011 disaster?' In response to this question, the participants were asked to rank the 18 terminal and 18 instrumental values. In the item ordering, the highest-ranked item was given 18 points, the second item 17 points and so on. Furthermore, they evaluated the value items in the current domestic degree of satisfaction in 5 grades.

Next, a network analysis was performed to explore the centrality of the multi-values space in benevolent sports activities. Calculating centrality is a major focus of social networking because it indicates what persons (or, in this case, what values) occupy critical positions in a value network. There are some centrality measures that are derived from the adjacency matrix and constitute different mathematical computations on the same underlying date.

Our first study used degree centrality and eigenvector centrality that are most commonly used by network analysts. Eigenvector centrality $\left(\mathrm{C}_{\mathrm{ev}}\right)$ is directly dependent on the centrality values of its connected neighbours. A high centrality value of the neighbours should result in a high centrality for the vertex under consideration [7].

For a given graph $G:=(V, E)$ with $|\mathrm{V}|$ vertices and $|\mathrm{E}|$ edges, let $A=\left(a_{v, t}\right)$ be the adjacency matrix, i.e. $a_{v, t}=1$ if vertex $v$ is linked to vertex $t$, and the numbers will increase depending on the number of connections. $a_{v, t}=0$ if there is no connections between the vertices. $\lambda$ is a scalar.

$$
\begin{aligned}
C_{e v}(i) & =\frac{1}{\lambda} \sum_{j=1}^{n} a_{i j} C_{e v}(j) \\
A C_{e v} & =\lambda C_{e v}
\end{aligned}
$$

In the present study, we used Katz centrality as a variant of eigenvector centrality, and we include the potential intimacy relationship within human values of co-operations. We assume $\beta$ $=0.06$ which means a one-eighteenth contributor's coefficient by total numbers of the terminal and instrumental values.

$$
x(i)=\alpha \sum_{j=1}^{n} a_{i j}(x(j)+\beta)
$$

In our past studies we examined the terminal value and instrumental value independently, but this study is a unique approach to mentioning the relationship between the terminal value and instrumental value. The related value structure could focus on the similarities and differences between the groups.

Furthermore, we apply a unique statistical approach to understand the difference between the groups, especially when verifying the similarity of the network centralities. The map layout was calculated using the Fruchterman-Reingold algorithm [8], which is a force-directed layout algorithm for constructing a graph to indicate the centralization of the multi-values' positioning. The purpose was to position the vertices of a graph in two or three-dimensional space so that all the edges were of approximately equal length and with as few crossing edges as possible. The force-directed algorithms achieved this by assigning forces among the set of vertices and the set of edges. The forces were applied to the vertices, pulling them closer 
together or pushing them further apart. This was iteratively repeated until the system reached an equilibrium state. Results showed some contributors that mapped centrally in the graph by value positions.

\section{National certified coaches}

\section{RESULTS AND DISCUSSION}

We discuss the three groups (national certified coaches, university students in sport science and university students in engineering) and the dimensions that they highlighted. The first group comprised the experienced athletic coaches and teachers. Their central cognitive societal terminal values (see Figure $1 \mathrm{~A}$
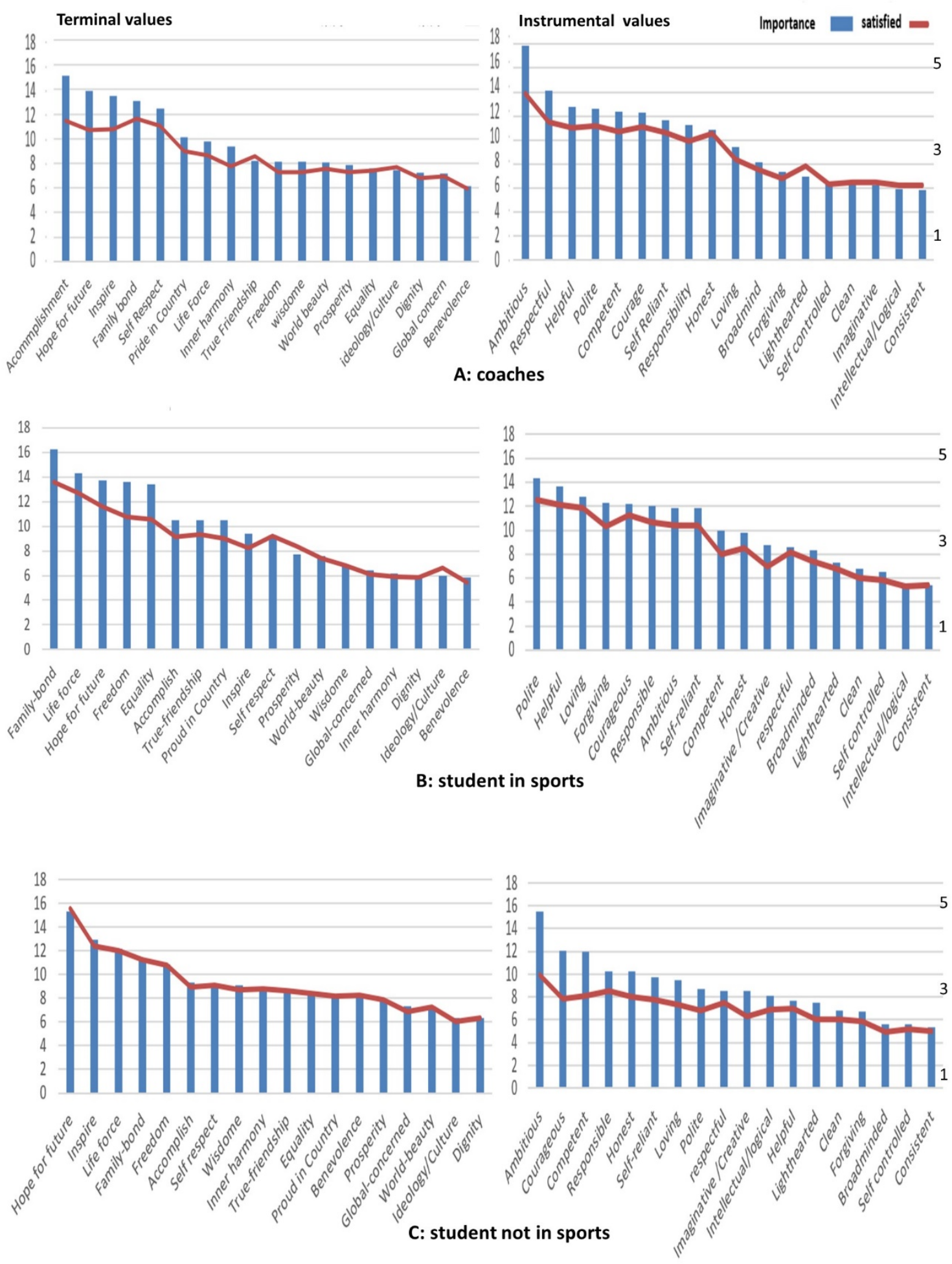
Figure 1. Order of importance and satisfaction degree of terminal / instrumental values in each group (A; national certified coaches, B; university students in sport science, C; university students not in sport science) assigned to benevolent sports activities after the 2011 disaster in Japan. Blue bar shows importance (1-18). Red line shows satisfaction grade (1-5)

left) were 'accomplishment; lasting contribution', 'hope for future', 'inspire', 'family bond (close companionship)' and 'self-respect (self-esteem)'. Other values located near the central space were 'pride in country', 'life force (zest for living)', 'inner harmony (freedom from inner conflict)', 'true friendship', 'freedom' and 'wisdom'.

In response to the spreading sense of helplessness in society after the 2011 disaster, the coaches might perceive sports as strengthening a sense of accomplishment and lasting contributions for future hope with human networking in their pride in country. They also might focus wisdom of life force and mental control (inner harmony) to overcome social terror and anxiety. The coaches might support the younger generation not only with technical instruction but also in character building for life management skills with keeping positive thought for future hope. 'Hope for the future' maintained its first-place or second-place ranking in past studies $[1,2]$. Family bond are maintaining the top fifth place.

These respondents' central cognitive societal instrumental values (see Figure $1 \mathrm{~A}$ right) of sports were 'ambitious (hard-working, aspiring)', 'respectful' 'helpful (welfare for others)'. Other values located near the central space were 'polite (courteous)', 'competent (capable, effective)', 'forgiving (willing to pardon others)', 'courageous (standing up for your beliefs)'. It is suggested a means to lasting contribution in society with courtesy. The coaches might regard interpersonal relationships as important for creating and re-enforcing societal networks. The top values of 'ambitious' was also ranked top place in the previous study [1,2].

The correlation between the importance and the satisfaction of terminal values in coaches was significant (terminal values; $r=0.96, p<0.01$, instrumental values; $r=0.98, p<0.01$ ). However, the upper items of importance (terminal value; accomplishment-lasting contribution, hope for future, inspire, instrumental values; ambitious, respectful, helpful, polite, competent, courage, self-reliant) tended to be less satisfaction. Due to seeking high satisfaction with high need of important value, divergence from satisfaction may occur.

\section{University students in sport science}

These students include athletes involved in national-level competitions. Their central cognitive societal terminal values of sports (see Figure 1 B left) were 'family bond (close companionship)' , 'life force', 'hope for future', 'freedom" and 'equality'. Other values located near the central space were 'accomplishment; lasting contribution', 'true-friendship', 'pride in country; NIPPON)', 'inspire' and 'self-respect'. Athletes might need close companionship and free equality circumstance because they are in a tough competition scene. They relatively lonely in their dedicated preparation for high-level competitions. The answer of 'life force (zest for living)' might be suitable for the tough competitors.

This group's central cognitive societal instrumental values (see Figure $1 \mathrm{~B}$ right) of sports were 'polite', 'helpful', 'loving', 'forgiving' and 'courageous'. The other value located nearest to the central space was 'responsible', 'ambitious', 'self-reliant', competent' and 'honest'. This group tends to be more altruistic than self-assertiveness. The result was different from the first and second place were 'ambitious' and 'courage' in the past study [2]. 
The correlation between the importance and the satisfaction of instrumental values in university students in sport science was significant (terminal values; $r=0.98, p<0.01$, instrumental values; $\mathrm{r}=0.97, \mathrm{p}<0.01$ ). However, the comparatively upper items (terminal values: family bond, life force, hope for future, freedom, equality) and upper and middle items (instrumental values; polite, helpful, loving, forgiving, courageous, responsible, ambitious, selfreliant, competent, honest, imaginative / creative) of importance in instrumental values tended to be less satisfaction.

\section{University students in engineering (not in sport science)}

These students are not coaches and athletes; i.e. they are not involved in sports. Thus, we should expect their answers to come from a different viewpoint. Their central cognitive societal terminal values of sports (see Figure $1 \mathrm{C}$ left) were 'hope for future', 'inspire', 'life force', family bond' and freedom'. Other values located near the central space were 'accomplishment', 'self-respect', 'wisdom', 'inner harmony' and 'true friendship'. These values might represent a realistic view of the values promoted by all levels of sport.

This group's central cognitive societal instrumental values (see Figure $1 \mathrm{C}$ right) of sports were 'ambitious', 'courageous', 'competent', 'responsible' and 'honest'. These respondents might regard sports achievement as the result of enterprise consistent, long-term effort. These might also reflect some key characteristics of sports.

The correlation between the importance and the satisfaction of instrumental values in university students not sport science was significant (terminal values; $r=0.95, p<0.01$, instrumental value; $r=0.94, p<0.01$ ). However, the comparatively upper items of importance in instrumental values (ambitious, courageous, competent, responsible, honest, self-reliant, loving, polite, respectful) tended to be less satisfaction.

\section{RELATIONS BETWEEN TERMINAL AND INSTRUCTION VALUES; PROUD LONELY ATHLETES}

Pride in country is centrally located in the social network centricity graph of the coach's and athletes' terminal value (see Figure 2, 3, 4). It would be regarded as an important value as well as family bond together with hope for future and a sense of accomplishment. Coaches' and Athletes' lives are difficult with many lonely days to overcome on the path to victories and records. They must feel very heavy pressure to be the last man standing on the podium. Therefore, the lonely coaches or athletes might desire family bond with people who share the same supreme desire, like fellow soldiers. Their central values in the graph might reflect ambition to challenge the world as a representative of their country and a will to show benevolence. Societal loneliness has been proposed as one explanation of the spread of anxiety within our highly advanced information society in some sociological discussions (the 'lonely crowd'[9], 'habits of the heart' [10] and 'bowling alone' [11]). [12]. However, if the loneliness is accompanied by some sense of societal pride, the combination might have the potential to offer a positive social force for the future [2]. In this study, the central items of instrumental values which would be approach to those terminal values were related with high intimacy. They are 'ambitious', 'competent', respectful', 'polite' and 'helpful'. These would be an ability to execute with a spirit of cooperation with recognition of others. Sports may be regarded or expected as an act of lasting contribution for society. One interesting result was shown. Compared to coaches, young athletes are looking for freedom (independence, free choice) as comparatively higher terminal values. Does the athlete want to seek a new freeway to future rather than the way the coach has decided? 
The difference between university students (not involved in sport) and coaches/athletes is that 'benevolence' (terminal value) and 'intellectual/logical' (instrumental value) were positioned relatively high. It may be abstract compared to the coach and athletes at the practice site, but they might be seeking an ideal value structure of sport. These similarity or difference would be explained more clearly in the next section of correspondence analysis.

Network graph analysis can verify the difference or similarity between some graphs. The correspondence analysis, which is one of 'centering resonance analysis' methods, was examined to clarify the similarities and compare the network centrality (see Figure 5). To maximise the relationship between row and column items, correspondence analysis sorts both rows and columns. As for the calculation result of the axial contribution ratio, the accumulated contribution ratio on the second axis is $100 \%$ (terminal values: $72.9 \%, 27.1 \%, 0.0 \%$; instrumental values: $63.5 \%$ : $36.5 \%, 0.0 \%$ ). The information on the graphed data was sufficiently representative.

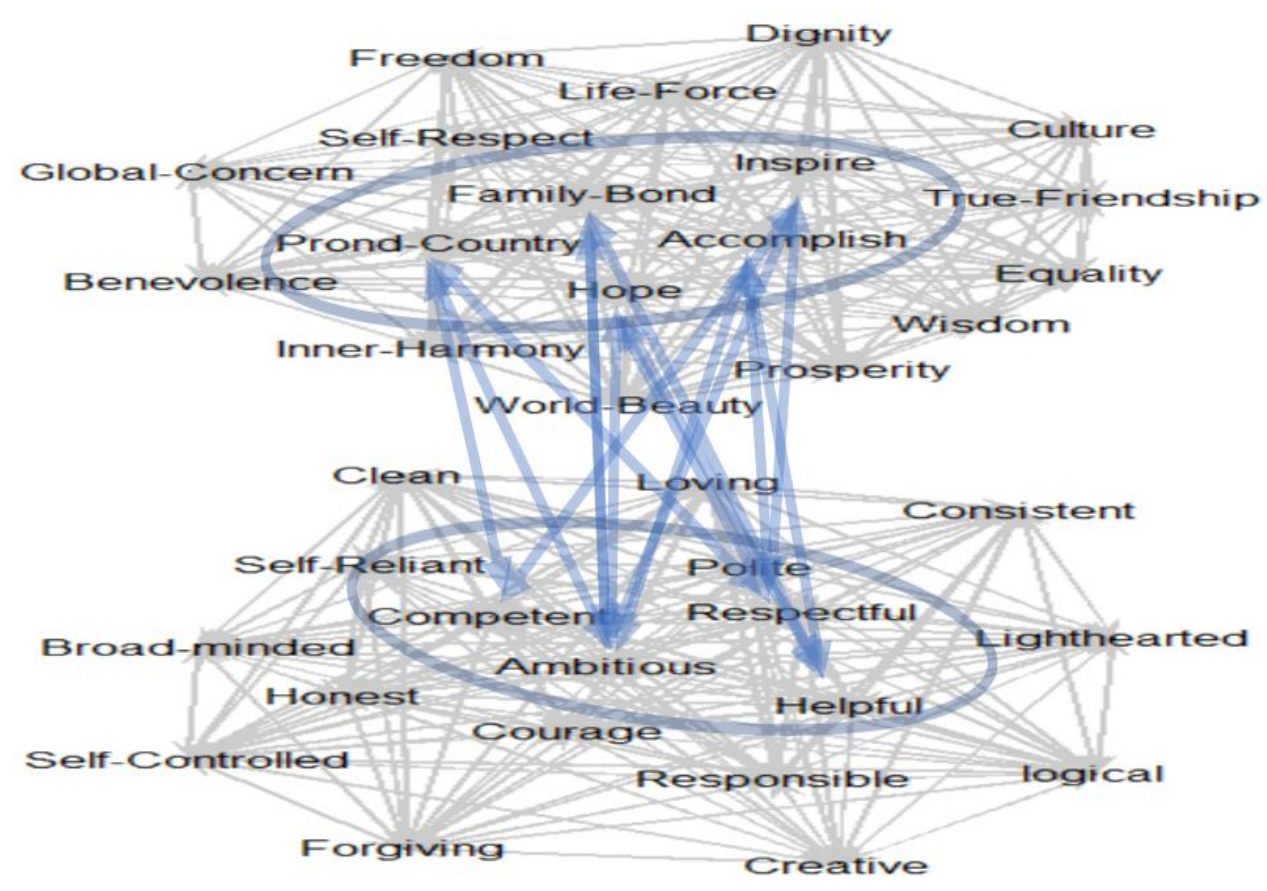


Figure 2. Mapping of terminal and instrumental values in national certified coaches assigned to benevolent sports activities after the 2011 disaster in Japan. High centrality items in terminal value network were intimately related to those in instrumental value network.

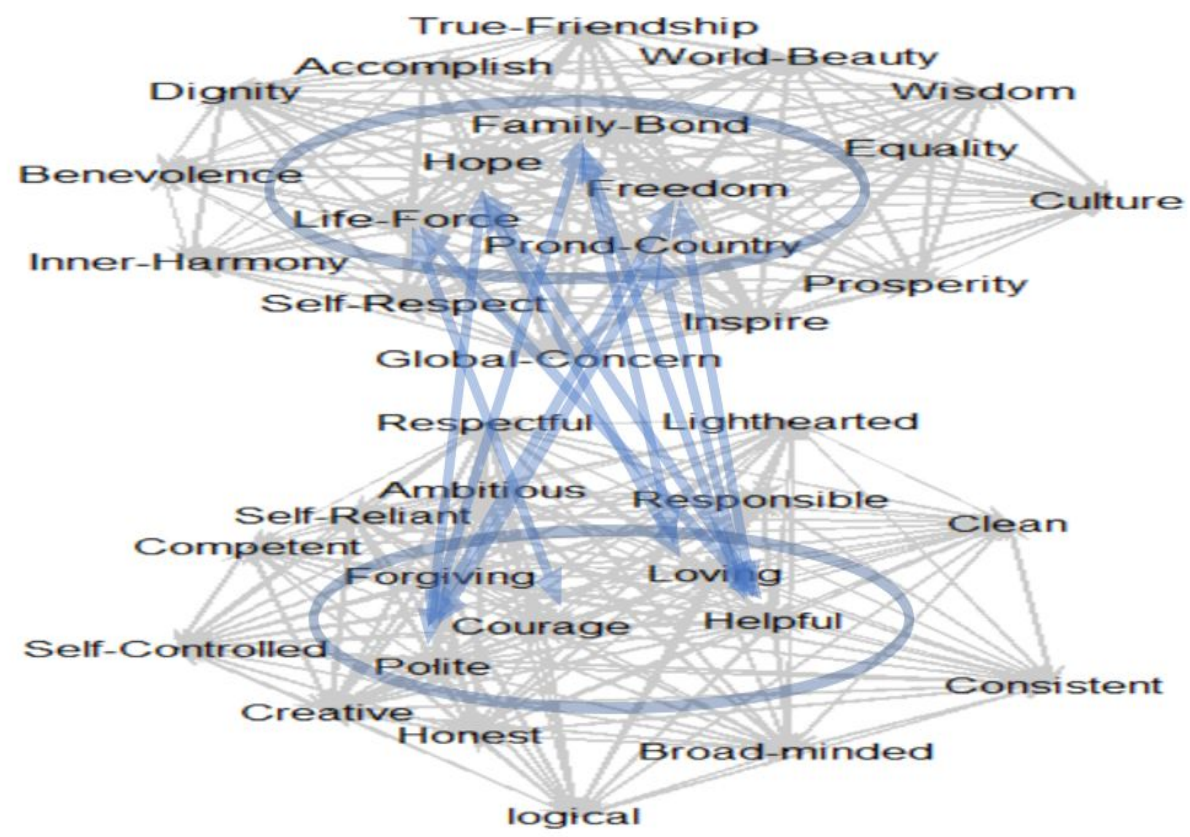

Figure 3. Mapping of terminal and instrumental values in university students in sports science assigned to benevolent sports activities after the 2011 disaster in Japan. High centrality items in terminal value network were intimately related to those in instrumental value network.

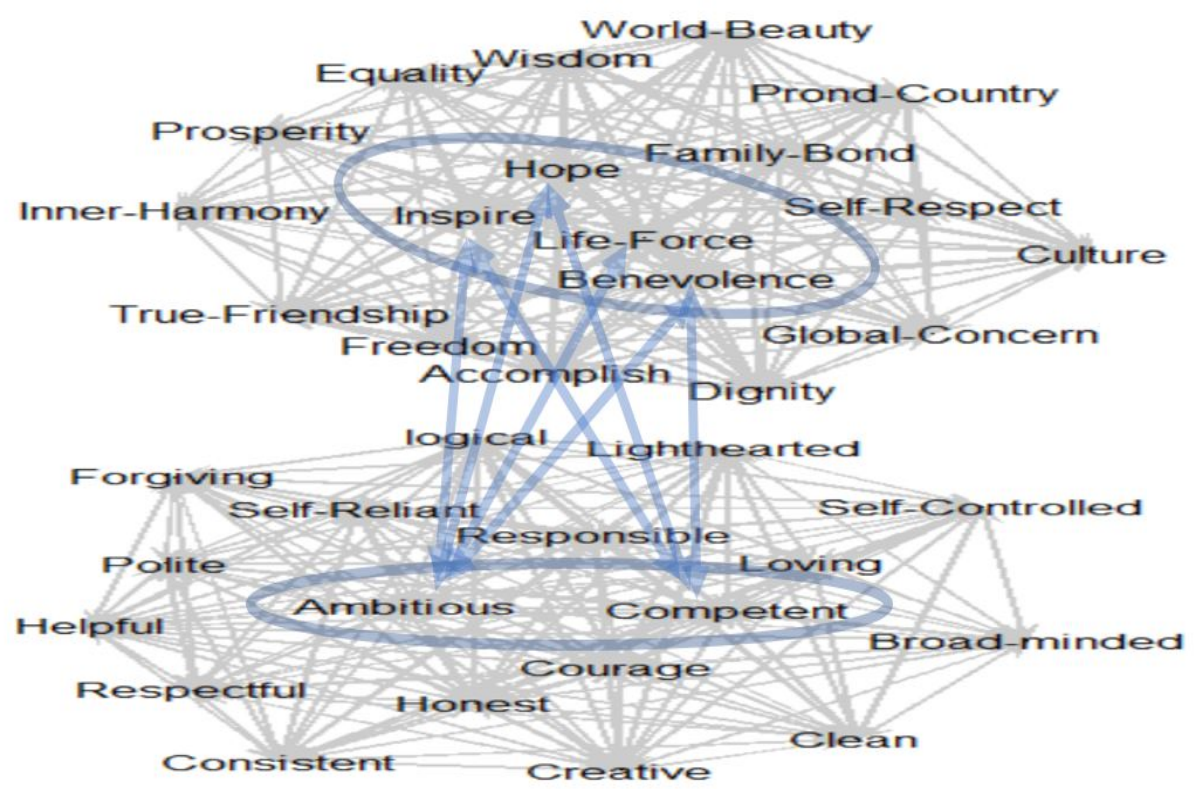

Figure 4. Mapping of terminal and instrumental values in university students in sports science assigned to benevolent sports activities after the 2011 disaster in Japan. High centrality items in terminal value network were intimately related to those in instrumental value network. 
There might be very few athletes who could think the ideal societal terminal values (e.g. 'benevolence', 'wisdom') as reported by non-athlete students (university students in engineering). The societal values reported by the athletes (university students in sport science) who dedicate their live to gruelling practice and competition were "equality" and 'freedom'. Equality and freedom (terminal value) may be cooperative values for competitive participation opportunity. National certified coaches highlighted values concerned with consistent competency (accomplishment: lasting contributions, self-respect) those mean social tactics value. The graph of terminal values suggested that the bridge connecting the athlete seeking competition opportunities with the coach supporting its execution would be the psychological attribution base (pride in country and family bond).

Characteristic instrumental value of athletes walking a long way is 'forgiveness'. Characteristics instrumental value positioned between coaches and athletes were 'polite', 'broad-minded' and 'helpful'.

It might be explained that pride in country and family bond discussed in sports might be the terminal wisdom leaded by social skill lie as 'broad-minded', 'polite' and 'helpful (welfare for others)'.

We reported that Japanese elite athletes might be motivated to take on the challenge of a longterm commitment to tough competition and might be regarded as the proud, lonely companions who express their proud country's will to recover from disaster. Reconstruction after major disaster takes a long time, and at first people could not see the light at the end of the tunnel. Only the brave, who were willing to embrace the challenge, could move society towards a positive future [2].

Lonely coaches and athletes could be supported by such social pride for their long term struggle for training under the pressure. It may also be related to the altruistic thought suggested by Rieseman. It would be explained in detail the concept of self-transcendence, the sixth desire of Maslow's hierarchy of needs as a motivational step beyond self-actualization [13]. Purely following the goal is a kind of heterogeneous and 


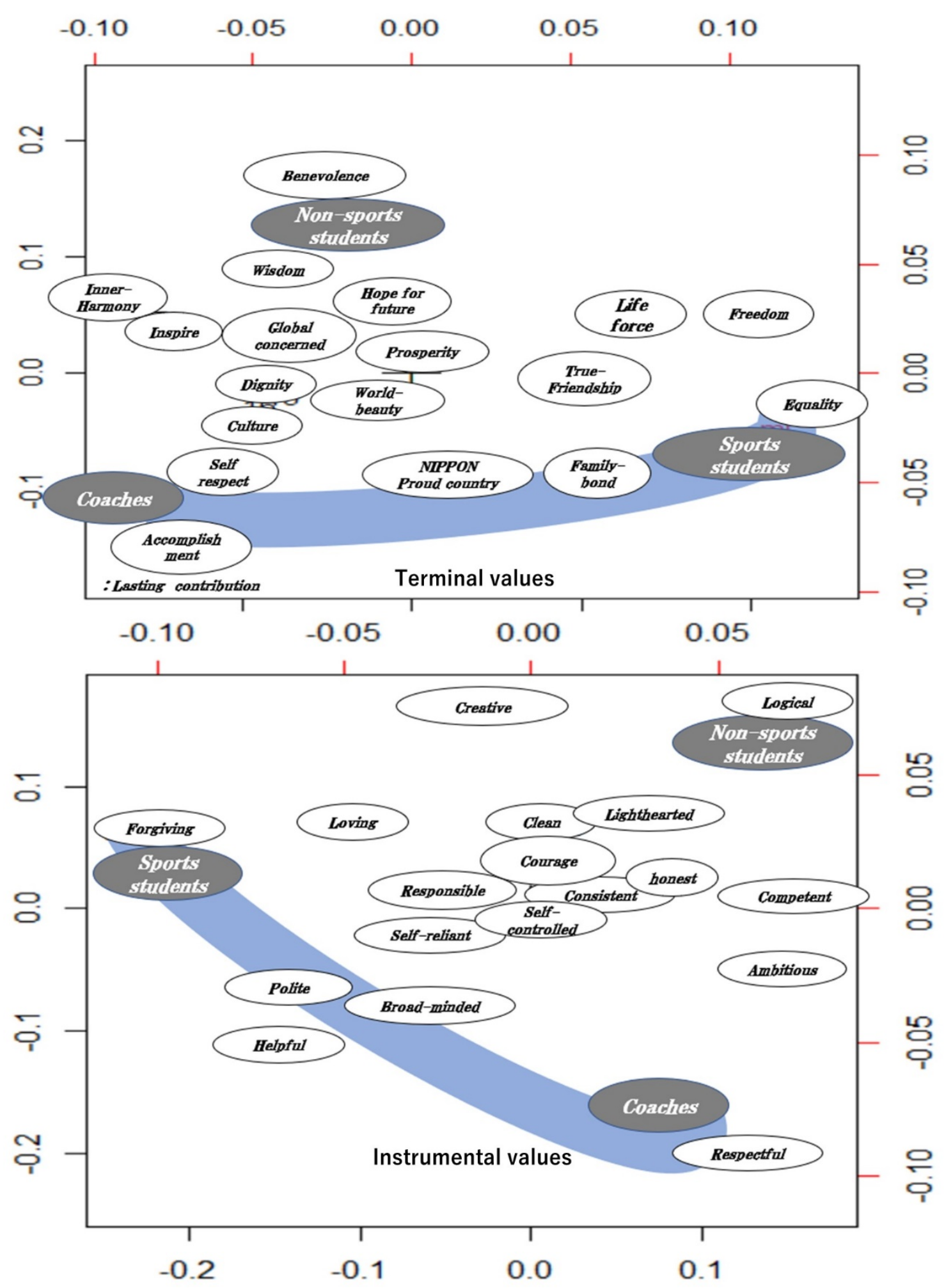

Figure 5. The space difference or similarity of the societal human values between coaches, sport students and non-sport students after the 2011 disaster in Japan as shown by centering resonance analysis (A: societal terminal values: B: societal instrumental values).

unique in a good sense. However, its mind is to co-evolve community and social philosophy. The originality may exert the power to connect society with intense change, high uncertainty, complex era. The value of sport life force means an extremely tactile information and create a direct communication community in the so-called information society. Pure pursuit of athletics could be feel the fulfillment not only in its achievement but also int its process time and may 
lead a high psychosocial health perspective. So, it can also be understood that it is the ontological and public value of sports as a terror management. Terror management provides one way of interpreting how people face the risks of life. Risk presents not only threatening dimension but also a more positive perspective, indicating that buffers against anxiety are provided not only by cultural and religious institutions but also by close human relationships [14]. Increasing the desire for relationships with others might act as a terror management mechanism. The values recognised in sports might indicate common ontological commitments: 'Human existence could reflect a dynamic balance of both biological and ontological values, such that humankind lives with not only one value but also freely selected and compounded multi-values to adapt to an increasingly complex environment and society' [1]. The societal human values expressed in sports by our lonely but proud athlete and coach can be regarded as identifying one valuable aspect of Japan's social capital. Accumulated values in sport that can provide hope for the next generation will be produced and disseminated toward opened society.

\section{ACKNOWLEDGEMENTS}

This study was partly supported by JSPS KAKENHI grant Number 16K01658 (20162018).

\section{References}

K. Sasaki, K. Komatsu, T. Yamamoto, Y. Ueno, T. Katsuta, and I. Kono, Cognitive societal human values of sports: After the 2011 disaster of Japan, Social Sciences, 2(1), 16, 2013, DOI: 10.11648/j.ss.20130201.11.

K. Sasaki, T. Yamamoto, Y. Ueno, T. Katsuta, I. Kono, Proud lonely athletes: Using network centrality analysis to clarify the societal values of sport after the 2011 disaster in Japan. Advances in Social Sciences Research Journal, 2(5), 83-92, 2015, DOI:10.14738/assrj.25.1173.

Y. Genda, Social sciences of hope, Tokyo University Press, 2009.

M. Tsuzuki, Study of hope, Minerva Shobo, 2004.

M. Rokeach, The nature of human values, The Free Press, 1973.

D. L. Paulhus and P. D. Trapnell, Terror management theory: extended or overextended? Psychological Inquiry, 8(1), 40-43, 1997.

B. Junker and F. Schreiber, Analysis of biological networks, John Wiley \& Sons, Inc., P78, 2008.

T. M. J. Fruchterman and E. M. Reingold, Graph Drawing by Force-directed Placement, Software - Practice and Experience, 21(11), 11291164, 1991.

D. Riesman, lonely crowd, Yale University Press, 1950.

E. R. N. Bellah, Habits of the heart: Individualism and commitment in American life, University of California Press, 1985.

R. D. Putnam, Bowling alone, Simon and Schuster, 2001.

A. Portes, Downsides of social capital, Proceedings of the National Academy of Sciences of the United States of America, 111(52),1840708, 2014.

M.E. Koltko-Rivera, Rediscovering the Later Version of Maslow's Hierarchy of Needs: Self-Transcendence and Opportunities for Theory, Research, and Unification, Review of General Psychology, 10(4), 302-317, 2006.

V. Florian, M. Mikulincer, and G. Hirschberger, The anxiety-buffering function of close relationships: Evidence that relationship commitment acts as a terror management mechanism, Journal of Personality and Social Psychology, 82 (4), 527-542, 2002. 